\title{
Holter monitoring of ventricular arrhythmias in a randomised, controlled study of intravenous streptokinase in acute myocardial infarction
}

\author{
Dimitrios Alexopoulos, Rory Collins, Stamatios Adamopoulos, Richard Peto, \\ Peter Sleight
}

\begin{abstract}
The occurrence of ventricular arrhythmias attributed to streptokinase treatment in acute myocardial infarction' is not well defined. Holter monitoring was performed for 24 hours in 81 patients with suspected acute myocardial infarction randomised in a ratio of $2: 1$ to intravenous streptokinase $1.5 \times 10^{6} \mathrm{IU}$ $(n=55)$ or placebo infusion $(n=26) 6.7$ hours (mean) after the onset of symptoms. No episodes of ventricular fibrillation were recorded. For the whole 24 hour period and during the first three hours after the start of treatment the incidence and frequency of ventricular arrhythmias were similar in the patients randomised to streptokinase and to placebo. But when the results in patients randomised "early" after the onset of symptoms of suspected acute myocardial infarction were analysed separately the frequency of abnormal complexes, pairs, runs, and repetitive arrhythmias seemed to be higher in patients allocated to streptokinase. This may reflect arrhythmias associated with reperfusion.
\end{abstract}

Streptokinase induced thrombolytic treatment of acute myocardial infarction can reopen occluded vessels, ${ }^{1-3}$ improve ventricular function, ${ }^{45}$ and prolong survival. ${ }^{6-8}$ It has, however, been suggested that reperfusion produced by thrombolytic treatment ${ }^{9-11}$ may be associated with an increase in the incidence of early ventricular arrhythmias. Conversely, because post-infarction ventricular arrhythmias are more common after larger infarcts, ${ }^{12}$ thrombolytic treatment, which seems to reduce infarct size, ${ }^{4}$ might be expected to decrease the overall incidence of arrhythmias. There are few controlled studies of the occurrence of ventricular arrhythmias in patients treated with fibrinolytic agents and those treated conventionally.

In the present study, 24 hour Holter monitoring was part of a double blind, placebo controlled randomised trial of intravenous streptokinase in acute myocardial infarction (ISIS-2 pilot $^{13}$ ) to assess the effects of thrombolytic treatment on ventricular arrhythmias. Arrhythmias occurring in the first few hours after the start of treatment (which might be related to reperfusion) and those occurring later during the first 24 hours (which might be related to infarct size) were assessed separately. Because some studies indicate that reperfusion rates may be inversely related to the time from onset of chest pain to the start of treatment, ${ }^{2}$ the influence of this delay on the incidence of ventricular arrhythmias was also investigated.

\section{Patients and methods}

PATIENTS

Between June 1983 and February 1985, 138 patients admitted to the John Radcliffe Hospital Coronary Care Unit were randomised in a placebo controlled study, details of which have been published elsewhere. ${ }^{13}$ Patients were eligible if the symptoms of suspected myocardial infarction had started less than 24 hours before and they had no clear indication for or contraindication to streptokinase, heparin, or aspirin (for example history of peptic ulcer, gastrointestinal bleed, stroke, bleeding disorder, recent surgery, resuscitation, or other injury, previous streptokinase treatment, aspirin allergy) and no life threatening condition other than myocardial infarction. A $2 \times 2 \times 2$ factorial randomised study design was used. ${ }^{13}$ Two thirds of all patients were allocated randomly to treatment with intravenous streptokinase (1 500000 IU) and one third to receive a matching placebo, ${ }^{13}$ started immediately and infused over about one hour in $20-100 \mathrm{ml}$ of physiological saline. Half of all patients were also allocated randomly to receive enteric coated aspirin ( $325 \mathrm{mg}$ every 48 hours) and half to receive matching placebo, one tablet each day for 28 days from a calendar pack, started immediately. Similarly, half of all patients were allocated randomly to receive heparin (1000 IU/h for 48 hours, starting 12 hours after the end of the streptokinase/placebo infusion) and half to receive no intravenous heparin, unless it was thought to be clearly indicated. In all other respects, physicians were free to use whatever additional treatment they considered necessary.

\section{RECORDING AND ANALYSIS OF ARRHYTHMIAS}

Holter tape recorders were available to start 24 hour electrocardiographic recording immediately before the start of trial treatment in 81 of the 138 Oxford patients (table 1). After the usual skin preparation modified V1 and V5 electrocardiographic leads were recorded on two channel Oxford Medilog II recorders. All patients had more than six hours recording. Two channel qualitative and quantitative electrocardiographic analysis was performed by a computerised non-triggered 
Table 1 Clinical characteristics

\begin{tabular}{|c|c|c|}
\hline Variable & Streptokinase $(n=55)$ & Placebo $(n=26)$ \\
\hline $\begin{array}{l}\text { Pre-randomisation data: } \\
\text { Age (yr) } \\
\text { Sex (\% male) } \\
\text { Systolic blood pressure (mm Hg) } \\
\text { Heart rate (beats/min) } \\
\text { Previous myocardial infarction (\%) } \\
\text { Diabetes mellitus }(\%) \\
\text { Time from onset of pain }(\mathrm{h}) \\
\text { Patients treated within } 6 \mathrm{~h} \\
\text { Patients treated later than } 6 \mathrm{~h} \\
\text { Infarct site. }\end{array}$ & $\begin{array}{cc}61.3 & (9.7) \\
78 & \\
130.1 & (20.5) \\
73.9 & (17.4) \\
16 & \\
16 & \\
6.7 & (3.2) \\
4.4 & (1.3) \\
9.5 & (2.8)\end{array}$ & $\begin{array}{cc}57 \cdot 6 & (8 \cdot 5) \\
73 & \\
127 & (12 \cdot 8) \\
73 & (12 \cdot 6) \\
12 & \\
0 & \\
6 \cdot 6 & (3 \cdot 1) \\
4 \cdot 4 & (1 \cdot 5) \\
9 \cdot 1 & (2 \cdot 4)\end{array}$ \\
\hline $\begin{array}{l}\text { Anterior-lateral (\%) } \\
\text { Inferior-posterior }(\%) \\
\text { Serum potassium on admission }(\mathrm{mmol} / \mathrm{l})\end{array}$ & $\begin{array}{l}44 \\
56 \\
3.9 \quad(0.5)\end{array}$ & $\begin{array}{ll}46 & \\
54 & \\
4 \cdot 1 & (0 \cdot 4)\end{array}$ \\
\hline $\begin{array}{l}\text { Post-randomisation data: } \\
\text { Antiarrhythmic agents (in the first } 24 \text { hours): } \\
\text { Lignocaine (\%) } \\
\text { Amiodarone (\%) }\end{array}$ & $\begin{array}{l}4 \\
2\end{array}$ & $\begin{array}{l}\mathbf{0} \\
\mathbf{0}\end{array}$ \\
\hline $\begin{array}{l}\text { Peak enzyme activities during hospital stay: } \\
\text { AST (IU/1) } \\
\text { LDH (IU/1) } \\
\text { Holter analysed (h) }\end{array}$ & $\begin{array}{cl}432 & (279) \\
887 & (736) \\
23 \cdot 1 & (2 \cdot 7)\end{array}$ & $\begin{array}{c}363(270) \\
1157(963) \\
21 \cdot 7 \quad(4 \cdot 6)\end{array}$ \\
\hline
\end{tabular}

template system consisting of a Z80A preprocessor and a DEC-LSI master, which had been used in our laboratory for the analysis of complex ventricular arrhythmias. ${ }^{14}$ The analysis was made without knowledge of the patient's treatment regimen. The following definitions were used:

(a) Abnormal complexes-abnormal QRSshaped complexes with a coupling interval of $>80 \%$ of the preceding $\mathbf{R R}$ interval.

(b) Ventricular extrasystoles-abnormal QRSshaped beats with a coupling interval $\leqslant 80 \%$ of the preceding RR interval.

(c) Pairs-two consecutive abnormal QRSshaped beats.

(d) Runs-three or more abnormal QRSshaped beats with a heart rate $<120 / \mathrm{min}$.

(e) Ventricular tachycardia-three or more consecutive abnormal QRS-shaped beats with a rate $\geqslant 120$ beats/min.

(f) Repetitive arrhythmias-pairs, runs, and ventricular tachycardia.

When pairs, runs, and ventricular tachycardia were detected by the computer the analysis was automatically stopped and the operator confirmed the pattern. Because of the varying QT interval all ventricular extrasystoles with coupling interval $\leqslant 400$ ms were screened carefully to identify and count the $R$ on-T extrasystoles accurately.

Arrhythmias recorded during the 24 hour study period in patients allocated to a streptokinase infusion were compared with those in patients allocated to a placebo infusion. Arrhythmias occurring in the first three hours after treatment started were also compared with those occurring in the remaining 21 hours. Though the factorial design does in principle allow separate assessment of the effects of aspirin and of heparin, it was not the intent of this arrhythmia study to consider such effects in any detail. Furthermore, because heparin was started 13 hours after the start of Holter monitoring, any differences caused by heparin could only be expected during the later part of the Holter monitoring.

\section{STATISTICAL ANALYSIS}

Baseline clinical characteristics were compared by the unpaired Student's $t$ test or $\chi^{2}$ test as appropriate. We compared the incidence of arrhythmia (percentage of patients with arrhythmias) and their frequency per hour (total number of arrhythmias for each patient divided by the hours of recording) among patients allocated to streptokinase and those allocated to placebo by the $\chi^{2}$ test and the Wilcoxon rank test, as appropriate. Values were expressed as mean (1 SD) or median and range.

\section{Results}

OCCURRENCE OF ARRHYTHMIAS

No episodes of ventricular fibrillation were seen in this small study. Overall there were no significant differences between the streptokinase and the placebo groups in the percentage of patients with ventricular arrhythmias (table 2). Similarly, there were no significant differences betwen the treatment groups in the percentage of patients with arrhythmias within three hours of the start of thrombolytic treatment and the percentage with arrhythmia during the remaining 21 hours. In eight patients, there was a sudden increase in ventricular arrhythmias soon after the start of the infusion. These episodes lasted less than 90 min and were followed by infrequent ventricular arrhythmias during the remaining monitored hours (fig 1). This pattern was more common (but not significantly so) in the streptokinase group (seven patients (13\%)) than in placebo group (one patient $(4 \%)$ ).

When patients treated early (that is within six hours) after the onset of symptoms were considered separately, there was no significant difference in the percentage with arrhythmias in the different treatment groups (table 2).

Table 2 Percentage of patients with ventricular arrhythmias recorded on Holter monitoring

\begin{tabular}{|c|c|c|c|c|c|c|}
\hline & \multicolumn{2}{|c|}{ All patients ( $n=81$ ) } & \multicolumn{2}{|l|}{$\leqslant 6 h(n=44)$} & \multicolumn{2}{|l|}{$6-24 h$} \\
\hline & $S K(n=55)$ & $P(n=26)$ & $S K(n=30)$ & $P(n=14)$ & $S K(n=25)$ & $P(n=12)$ \\
\hline $\begin{array}{l}\text { Abnormal complexes } \\
\text { Extrasystoles } \\
\text { R on Ts } \\
\text { Pairs } \\
\text { Runs } \\
\text { V tach } \\
\text { Repetitive }\end{array}$ & $\begin{array}{r}100 \\
100 \\
73 \\
82 \\
89 \\
62 \\
93\end{array}$ & $\begin{array}{r}100 \\
100 \\
88 \\
88 \\
77 \\
62 \\
92\end{array}$ & $\begin{array}{r}100 \\
100 \\
83 \\
90 \\
97 \\
63 \\
97\end{array}$ & $\begin{array}{r}100 \\
100 \\
93 \\
93 \\
79 \\
64 \\
100\end{array}$ & $\begin{array}{r}100 \\
100 \\
60 \\
72 \\
80 \\
60 \\
88\end{array}$ & $\begin{array}{r}100 \\
100 \\
83 \\
83 \\
75 \\
58 \\
83\end{array}$ \\
\hline
\end{tabular}

$P$, placebo; SK, streptokinase; V tach, ventricular tachycardia. 
Figure 1 Distribution of abnormal complexes from a patient with sudden shortly after the start of streptokinase infusion. increase in arrhythmias

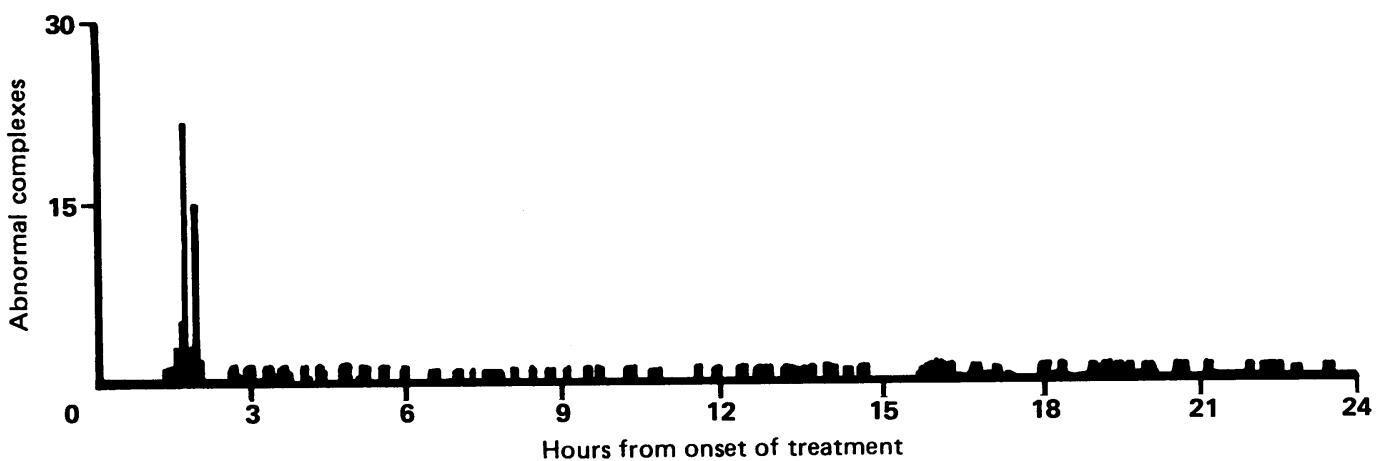

Table 3 Median frequency (range) per hour of ventricular arrhythmias

\begin{tabular}{|c|c|c|c|c|c|c|}
\hline & \multicolumn{2}{|c|}{ All patients } & \multicolumn{2}{|l|}{$\leqslant 6 h$} & \multicolumn{2}{|l|}{ 6-24h } \\
\hline & $S K$ & $P$ & $S K$ & $P$ & $S K$ & $P$ \\
\hline Abnormal complexes & $\begin{array}{l}3.9 \\
(0 \cdot 2-390)\end{array}$ & $\begin{array}{l}2 \cdot 7 \\
(0 \cdot 1-76)\end{array}$ & $\begin{array}{l}7 \cdot 9 \\
(0.5-390)\end{array}$ & $\begin{array}{l}2 \cdot 7 \dagger \\
(0 \cdot 1-76)\end{array}$ & $\begin{array}{l}2 \cdot 4 \\
(0 \cdot 2-11)\end{array}$ & $\begin{array}{l}2 \cdot 7 \\
(0 \cdot 3-69)\end{array}$ \\
\hline Extrasystoles & $\begin{array}{l}5 \cdot 0 \\
(0 \cdot 3-889)\end{array}$ & $\begin{array}{l}5 \cdot 8 \\
(0 \cdot 5-497)\end{array}$ & $\begin{array}{l}9 \cdot 7 \\
(0.6-889)\end{array}$ & $\begin{array}{l}5.8 \\
(0.5-497)\end{array}$ & $\begin{array}{l}3 \cdot 1 \\
(0 \cdot 3-71)\end{array}$ & $\begin{array}{l}8 \cdot 8 \\
(2 \cdot 1-142)\end{array}$ \\
\hline$R$ on $T s$ & $\begin{array}{l}0.2 \\
(0-41)\end{array}$ & $\begin{array}{l}0 \cdot 2 \\
(0-41)\end{array}$ & $\begin{array}{l}0 \cdot 2 \\
(0-41)\end{array}$ & $\begin{array}{l}0 \cdot 2 \\
(0-26)\end{array}$ & $\begin{array}{l}0 \cdot 1 \\
(0-1 \cdot 3)\end{array}$ & $\begin{array}{l}0 \cdot 2 \\
(0-41)\end{array}$ \\
\hline Pairs & $\begin{array}{l}0.3 \\
(0-39)\end{array}$ & $\begin{array}{l}0 \cdot 2 \\
(0-15)\end{array}$ & $\begin{array}{l}0 \cdot 7 \\
(0-39)\end{array}$ & $\begin{array}{c}0 \cdot 2 \ddagger \\
(0-15)\end{array}$ & $\begin{array}{l}0 \cdot 2 \\
(0-1 \cdot 3)\end{array}$ & $\begin{array}{l}0 \cdot 2 \\
(0-6 \cdot 4)\end{array}$ \\
\hline Runs & $\begin{array}{c}0.3 \\
(0-24)\end{array}$ & $\begin{array}{c}0 \cdot 1 \\
(0-12)\end{array}$ & $\begin{array}{c}0.7 \\
(0-24)\end{array}$ & $\begin{array}{c}0 \cdot 2^{\star} \\
(0-12)\end{array}$ & $\begin{array}{l}0 \cdot 2 \\
(0-1 \cdot 2)\end{array}$ & $\begin{array}{l}0 \cdot 1 \\
(0-2 \cdot 8)\end{array}$ \\
\hline V tach & 0 & $(0-0.3)$ & $\begin{array}{l}0.1 \\
(0-3 \cdot 3)\end{array}$ & $(0-0.3)$ & 0 & 0 \\
\hline Repetitive & $\begin{array}{l}0.8 \\
(0-60)\end{array}$ & $\begin{array}{l}0.3 \\
(0-28)\end{array}$ & $\begin{array}{l}1 \cdot 7 \\
(0-60)\end{array}$ & $\begin{array}{c}0.4 \dagger \\
(0 \cdot 1-28)\end{array}$ & $\begin{array}{l}0 \cdot 3 \\
(0-2 \cdot 3)\end{array}$ & $\begin{array}{l}0 \cdot 3 \\
(0-9 \cdot 2)\end{array}$ \\
\hline
\end{tabular}

$\star 2 p<0.02 ; \nmid 2 p<0.01 ; \ddagger 2 p<0.005$.

See footnote to table 2 for abbreviations.

\section{SK allocated}

Placebo allocated
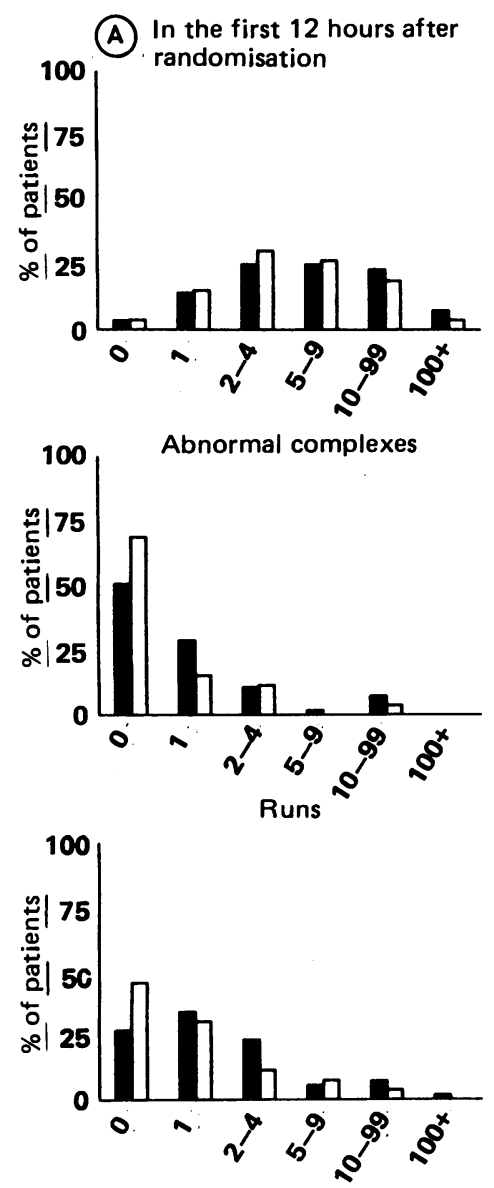

Repetitive arrhythmias
(B) I In hours 13-24 after

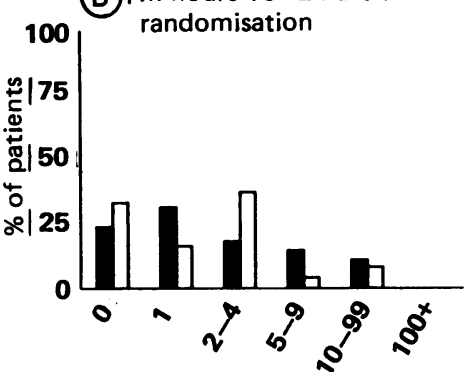

Abnormal complexes
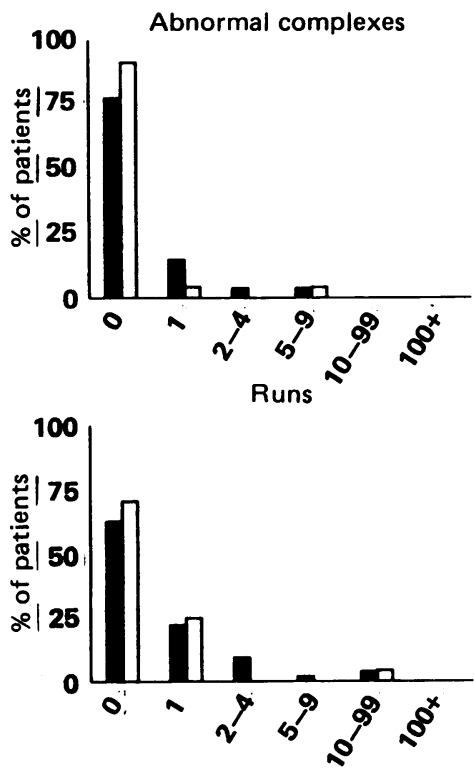

Repetitive arrhythmias
Figure 2 Percentage of patients and mean number of abnormal complexes, runs, and repetitive arrhythmias seen during the first 12 hours and 13-24 hours from randomisation. SK, streptokinase.
HOURLY FREQUENCY OF ARRHYTHMIAS

Overall there were no significant differences between the streptokinase and the placebo groups in the average hourly frequency of ventricular arrhythmias (table 3 ). The hourly frequency of arrhythmias recorded within three hours of the onset of treatment and during the remaining 21 hours of recording was similar in the treatment and placebo groups. But for patients treated within six hours of the onset of pain there were significant differences between the treatment groups in the frequency of abnormal complexes, of pairs, of runs, and of repetitive arrhythmias (table 3). This seemed to be largely the result of an increase in such arrhythmias during the first 12 hours after treatment (figs 2-4) and was not apparent among patients treated 6-24 hours after the onset of pain (table 3).

\section{Discussion}

There is little detailed information from Holter monitoring on the effects of fibrinolytic treatment on arrhythmias. To our knowledge, only two previous studies have attempted quantitative analysis of post-thrombolysis arrhythmias by continuous electrocardiographic monitoring. Willems et al used a low initial intravenous streptokinase dose regimen (250 000 IU initially, followed by 100000 IU/ hour for 24 hours) and they found no overall difference in the number of extrasystoles. ${ }^{15}$ Differences in baseline arrhythmias and in the use of antiarrhythmic agents, however, were considered by these workers to have limited the value of their study. More recently, in a study of 750000 or $1500000 \mathrm{IU}$ of intravenous 


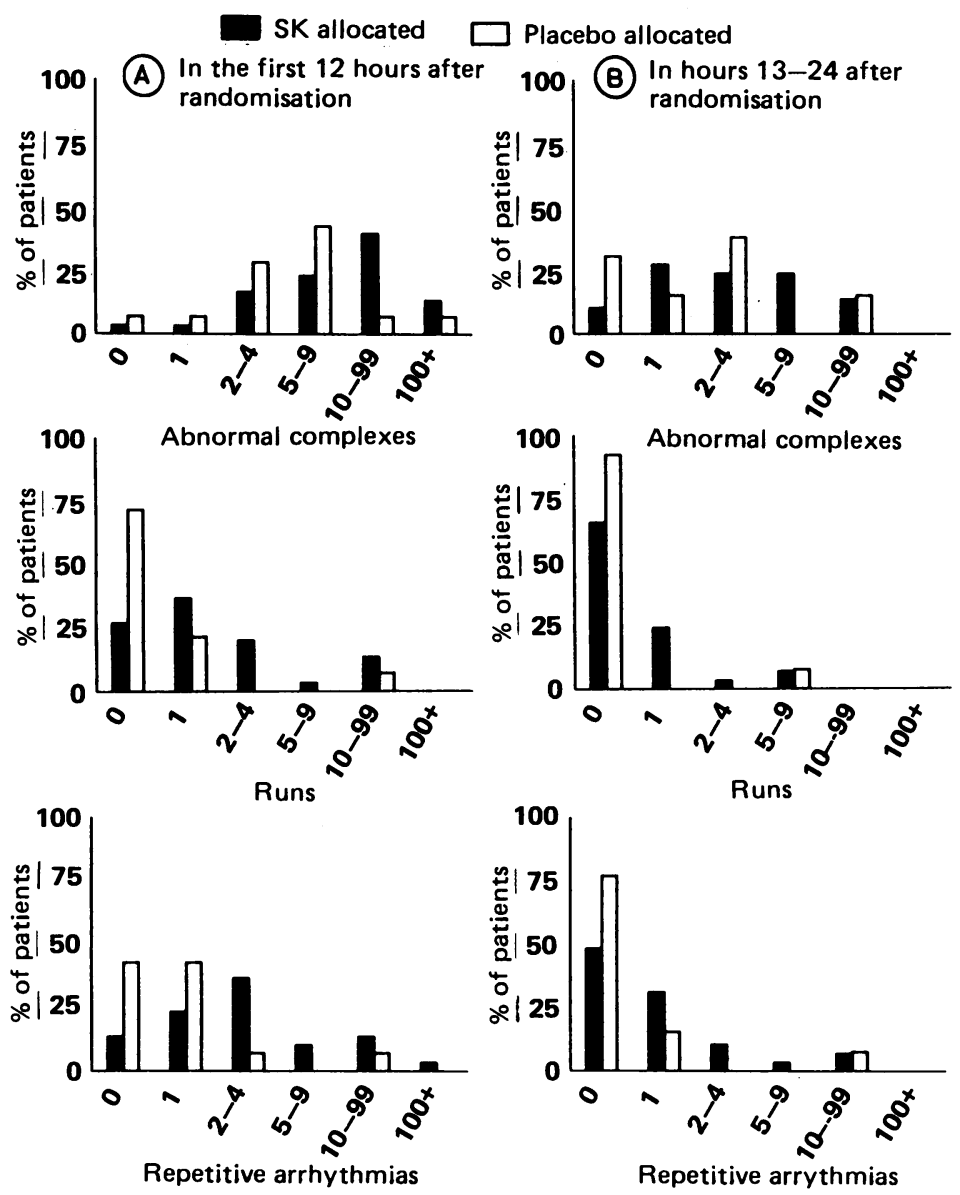

Figure 3 Percentage of patients treated within six hours from onset of symptoms and mean number of abnormal complexes, runs, and repetitive arrhythmias seen during the first 12 hours and 13-24 hours from randomisation. SK, streptokinase.
SK allocated
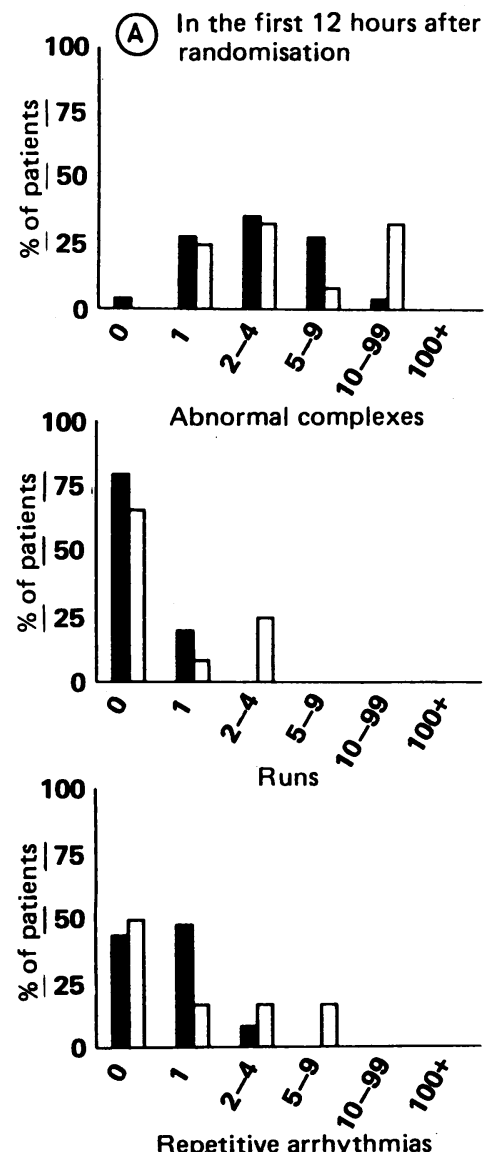

Repetitive arrhythmias

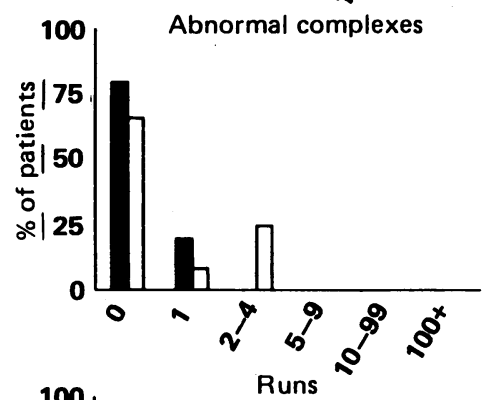

Placebo allocated
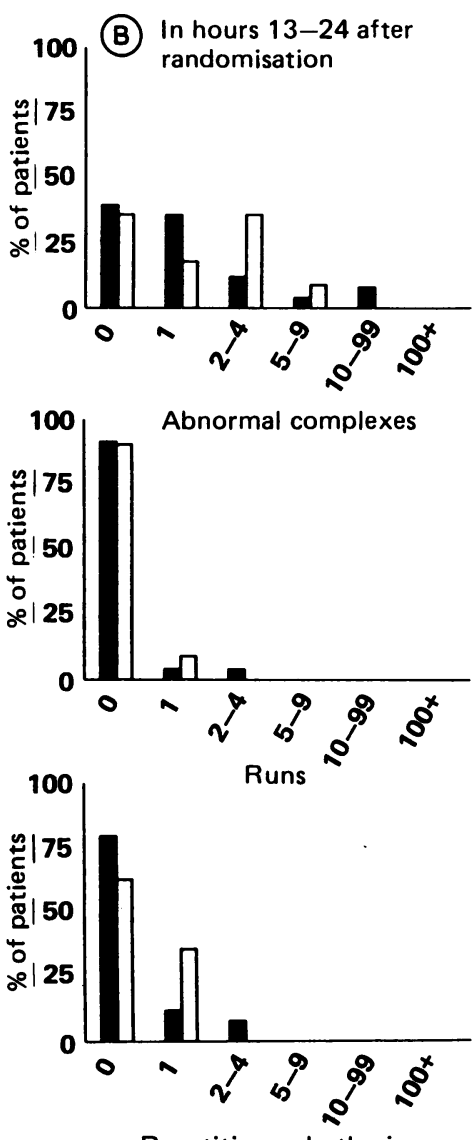

Figure 4 Percentage of patients treated more than six hours from onset of symptoms and mean number of abnormal complexes, runs, and repetitive arrhythmias seen during the first 12 hours and 13-24 hours from randomisation. SK, streptokinase. streptokinase given over about $2 \cdot 5$ hours), Cercek et al reported on the percentage of patients with arrhythmias attributed to reperfusion defined by non-invasive indices. ${ }^{16}$ There was, however, no control group in this study with which to compare the patients given fibrinolytic treatment.

In the large GISSI trial conventional (that is non-Holter) electrocardiographic monitoring detected early arrhythmia in only $1.2 \%$ of the patients allocated to streptokinase treatment but in this trial the frequency of early arrhythmias was not recorded in the open-control patients. ${ }^{7}$ In a subgroup of 433 patients participating in GISSI, arrhythmic events were recorded by computerised coronary care or Holter monitoring during the first two hours after randomisation. No clear differences were demonstrated between the patients allocated to the streptokinase and control groups. ${ }^{17}$

Ventricular fibrillation was not seen in any patient in the present Holter study, but this is not surprising given its small size. In the large ISIS-2 trial, the observed incidence of ventricular fibrillation during the first 24 hours after the start of treatment was similar in the patients allocated to streptokinase and placebo $(2 \cdot 8 \% \vee 2 \cdot 8 \%$, unpublished data), while ventricular fibrillation during hospital admission was somewhat less common in patients allocated to streptokinase $(4.3 \%$ v $4.9 \%)$. A similar, non-significantly lower incidence of ventricular fibrillation in hospital was also seen in the GISSI and recent trials of other fibrinolytic agents. ${ }^{18} 19$

The intention of the present Holter study was to assess the effects of streptokinase on arrhythmias in a randomised controlled study. Streptokinase did not seem to increase the overall percentage of patients with arrhythmia or the overall frequency of arrhythmias among the patients entered in the study, though there was a suggestion that streptokinase might be associated with an increased frequency of abnormal complexes, of runs, and of repetitive arrhythmias among patients treated early after the onset of pain. Because angiographic data were not available for patients in this study, this apparent excess of arrhythmias cannot be attributed definitely to myocardial reperfusion, though this seems to be a plausible hypothesis worthy of further study.

In this study intravenous streptokinase treatment seemed to have a low arrhythmogenic potential (and, indeed, larger studies suggest that serious arrhythmias may be less common with fibrinolytic treatment). Consequently, there may be little need for treatment with prophylactic antiarrhythmic agents in patients given fibrinolytic treatment, particularly in view of the lack of evidence for any benefits of these agents ${ }^{20}$ in the treatment of suspected acute myocardial infarction when fibrinolytic treatment is not used.

RC was supported by the British Heart Foundation. Hoechs (UK) and Behringwerke (Germany) provided supported. The study, however, was conducted, analysed, and interpreted study, however, was conducted,

We thank Dr Sarah Parish and Mr Paul Appleby for assistance with computer programming. 
1 Rentrop P, Blanke H, Karsch KR, Kaiser H, Kostering H, Leitz $\mathrm{K}$. Selective intracoronary thrombolysis in acute myocardial infarction and unstable angina pectoris. Circulation 1981;63:307-17.

2 Schroder R, Biamino G, v. Leitner ER, et al. Intravenous short-term infusion of streptokinase in acute myocardial short-term infusion of streptokinase in
infarction. Circulation 1983;67:536-48.

$3 \mathrm{Khaja} \mathrm{F}$, Walton JA Jr, Brymer JF, et al. Intracoronary fibrinolytic therapy in acute myocardial infarction: repor of a prospective randomized trial. $N$ Engl J Med 1983;308:1305-11

4 I.S.A.M. Study Group. A prospective trial of intravenous streptokinase in acute myocardial infarction (ISAM) mortality, morbidity and infarct size at 21 days. $N$ Engl $J$ Med 1986;314:1465-71.

5 White HD, Norris RM, Brown MA, et al. Effect of intravenous streptokinase on left ventricular function and early survival after acute myocardial infarction. $N$ Engl $J \mathrm{Med}$ 1987;317:850-5.

6 Yusuf S, Collins R, Peto R, et al. Intravenous and intracoronary fibrinolytic therapy in acute myocardia infarction: overview of results on mortality, reinfarction and side-effects from 33 randomized controlled trials. Eur Heart $J$ 1985;6:556-85.

7 Gruppo Italiano per lo Studio della Streptochinasi nell' Infarto Miocardico (GISSI). Effectiveness of intravenous thrombolytic treatment in acute myocardial infarction. thrombolytic treatment

8 ISIS-2 (Second International Study of Infarct Survival) Collaborative Group. Randomised trial of intravenous streptokinase, oral aspirin, both, or neither among 1718 cases of suspected acute myocardial infarction: ISIS-2 Lancet 1988;ii:349-60.

9 Goldberg S, Greenspan AJ, Urban PL, et al. Reperfusion arrhythmias: a marker of restoration of antegrade flow during intracoronary thrombolysis for acute myocardial infarction. Am Heart J 1983;105:26-32.
10 Miller FC, Krucoff MW, Satler LF, et al. Ventricular arrhythmias during reperfusion. Am Heart $J$ 1986;112: 928-32.

11 Cercek B, Horvat $M$. Arrhythmias with brief, high-dose intravenous streptokinase infusion in acute myocardial infarction. Eur Heart $J$ 1985;6:109-13.

12 Roberts R, Husain A, Ambos HD, Oliver GC, Cox JR Jr, Sobel BE. Relation between infarct size and ventricular Sobel BE. Relation between infarct size

13 International Studies of Infarct Survival. Randomized factorial trial of high-dose intravenous streptokinase, of oral torial trial of high-dose intravenous streptokinase, of oral
aspirin and of intravenous heparin in acute myocardial aspirin and of intravenous heparin in
infarction. Eur Heart $J$ 1987;8:634-42.

14 Alexopoulos D, Yusuf S, Bostock J, Johnston JA, Sleight P, Yacoub $\mathrm{MH}$. Ventricular arrhythmias in long term survivors of orthotopic and heterotopic cardiac transplantation. Br Heart J 1988;59:648-52.

15 Willems JL, Theiss W, Lubcke P. Arrhythmias in patients of a multicenter trial on streptokinase treatment in acute myocardial infarction. Acta Med Scand [Suppl] 1981; 648:75-84.

16 Cercek B, Lew AS, Laramee P, Shah PK, Peter TC, Ganz W. Time course and characteristics of ventricular arrhythmias after reperfusion in acute myocardial infarction: $\mathrm{Am}$ $J$ Cardiol 1987;60:214-8.

17 Furlanello F, Bettini R, Stirpe E, et al. G.I.S.S.I.: Studio dell aritmie. G Ital Cardiol 1987;17:73-8.

18 ASSET Study Group. Trial of tissue plasminogen activator for mortality reduction in acute myocardial infarction. for mortality reductio

19 AIMS Trial Study Group. Effect of intravenous APSAC on mortality after acute myocardial infarction: preliminary report of a placebo-controlled trial. Lancet 1988;i:545-9.

20 MacMahon S, Collins R, Peto R, Koster RW, Yusuf S. Effects of prophylactic lidocaine in suspected acute myocardial infarction: an overview of results from the randomized, controlled trials. JAMA 1988;260:1910-6. 